\section{Hyperbaric oxygen treatment of superficial soft tissue lesions in children with oncologic disease}

\author{
Eleonora Cesca, 1 Giacomo Garetto,2 \\ Emanuela Frascella, ${ }^{3}$ Simone Cesaro, ${ }^{3}$ \\ Patrizia Dall'Igna, ${ }^{1}$ Giovanni Cecchetto' \\ 1Department of Pediatrics, ${ }^{2}$ Hyperbaric \\ Medicine Unit, 3 Pediatric Hematology- \\ Oncology, University Hospital of Padova, \\ Italy
}

\begin{abstract}
This study aimed to assess the feasibility and results of hyperbaric oxygen therapy (HOT) as supportive treatment of lesions of superficial soft tissues in children with oncological diseases. This was a retrospective analysis and review of all records of children observed at the Pediatric Hematology-Oncology Department of the University of Padova and treated adjuvantly with HOT. Between 1996 and 2010, 12 patients ( 5 males and 7 females, median age 7 years, range 0.5 -16) underwent HOT. The effectiveness of HOT varied according to the lesion treated. Ten out of 12 patients were cured. Efficacy was most questionable in 2 patients with skin graft and flaps at risk. Compliance to therapy was close to $100 \%$. In just one case, HOT was interrupted for the appearance of local skin metastases close to the site of primary tumor. HOT showed itself to be safe and effective in most patients even those immunocompromised or critically ill.
\end{abstract}

\section{Introduction}

There are large variations in clinical opinion and practice concerning local and systemic treatment of skin and soft tissue lesions, and a wide range of therapeutic strategies are adopted. Among these, HOT is widely recommended in adults on the basis of scientific evidence or well-established clinical experience.1,2 HOT is a bloodless treatment implemented by breathing pure oxygen $\left(\mathrm{O}_{2}\right)$ in hyperbaric chambers, where air pressures are greater than those of the ground atmosphere (1 atmosphere absolute, ATA). Therapeutic action depends on the increased amount of $\mathrm{O}_{2}$ that is conveyed to the tissues dissolved in plasma. Since $\mathrm{O}_{2}$ in high doses is toxic to normally perfused tissues, particularly brain and lungs, HOT should not continue for longer than 1-2 h. ${ }^{1}$

There are few data concerning the treat- ment of complicated lesions of skin and superficial soft tissue with HOT therapy in children.3-11 To date, standard regimens, used for adults for the treatment of various diseases, are not available in children and it is fairly obvious that every child requires an individualized treatment. Therefore, the application of HOT therapy in this age group requires, beside the knowledge of the basic principles that regulate HOT, also a close collaboration between the different specialists involved in the care of the child. Moreover, adaptation of medical instruments and $\mathrm{O}_{2}$ delivery systems according to patient age is required. ${ }^{9,10}$

The aim of the study was to assess the feasibility and results of HOT therapy as supportive treatment of diseases of skin and superficial soft tissues in a particular group of children with oncological diseases.

\section{Materials and Methods}

Between January 1996 and December 2010, 31 consecutive children were treated in the Department of Pediatrics of the University Hospital of Padova with adjuvant HOT therapy for skin and soft tissue lesions. The records of 12 of 31 patients treated for oncological disorders were reviewed. Patients were 5 males and 7 females, age ranged from 6 months to 16 years (median 7 years).

Preparation of the pediatric patient to HOT therapy required: i) informing parents and adolescents on how HOT is performed; ii) teaching the patient how to equilibrate middle ear pressure by swallowing, yawning, chewing, or sucking a pacifier; iii) use of bilateral myringotomy in smaller children; iv) chest Xray to rule out underlying diseases predisposing to tension pneumothorax and barotraumas, such as pulmonary cysts, emphysema, asthma. In addition, heart function was checked with ECG.

HOT was administered in a multi-person hyperbaric chamber. Patients entered the chamber with the physician and sometimes with a family member. In hyperbaric chambers $\mathrm{O}_{2}$ has to be inhaled through an uncuffed endotracheal tube, a cushioned face mask or a head helmet. The $\mathrm{O}_{2}$ delivery system was adapted to the age and condition of the patient. ${ }^{9}$ In particular, since it is impossible to apply a facial-mask in patients under the age of one year, the smallest children were introduced from the belly to the head into a classic adult head helmet [Figure 1]. Standard treatment protocol included HOT at a pressure of 2.0 up to 2.5 ATA (in adults 3 ATA are normally used). ${ }^{9}$ Patients breathed pure $\mathrm{O}_{2}$ for three 25 min periods, interrupted by two 5 -min air breaks to avoid $\mathrm{O}_{2}$ cerebral toxicity. Treatment
Correspondence: Eleonora Cesca, Pediatric Surgery, Department of Pediatrics, University Hospital of Padova, via Giustiniani 3, 35128 Padova, Italy.

Tel. +39.049.8213690 - Fax: +39.049 .8211781 .

E-mail: elecesca@yahoo.it

Key words: hyperbaric oxygen treatment, superficial soft tissue lesions, oncological children.

Contributions: EC, CG, wrote the manuscript, designed the study and are guarantors; PD'I contributed to the writing of the manuscript; GG, SC, $\mathrm{EF}, \mathrm{GC}$ provided clinical and methodological advice, and commented on drafts of the manuscript.

Conflict of interest: the authors report no conflicts of interest.

Received for publication: 19 0ctober 2011. Accepted for publication: 24 October 2011.

This work is licensed under a Creative Commons Attribution NonCommercial 3.0 License (CC BYNC 3.0).

(C) Copyright E. Cesca et al., 2012

Licensee PAGEPress, Italy

Pediatric Reports 2012; 4:el

doi:10.4081/pr.2012.e1

was normally administered once daily for 5 days each week, with a schedule of up to a maximum of 60 sessions. ${ }^{1,9}$ The precise therapeutic schema was not the same for all children, but was tailored according to their disease and continued on the basis of the results achieved. For each patient, demographic and disease-related data, such as sex, age, underlying disease, indication to HOT, number of sessions, duration and pressures of $\mathrm{HBO}$, effects and outcome after this supportive therapy, side effects and degree of compliance to therapy, were collected. After HOT all patients were followed for a median duration of five years (range 1-10 years). This retrospective study was approved by the ethics committee at Padova University Hospital.

\section{Results}

The 12 patients were divided into 6 groups according to indication for HOT therapy. Their clinical features, schema and results of treatment are summarized in Table 1.

Group 1 included one male (patient n. 1.1) affected by necrotising fasciitis (NF) of the buttock-perineal region and one female (patient n. 1.2) with gas gangrene (GG) of the head/neck region (Figure 2A). In both cases, neutropenia was seen at the time of presentation of infection. The underlying malignancies 
were acute lymphoblastic leukemia (ALL) (patient n. 1.1) and neuroblastoma (patient n. 1.2). The diagnosis of GG was made on the basis of history, fever, tachycardia, severe pain, septic shock, appearance of head and neck superficial tissue, odor, crepitation of tissue, and presence of gas in X-ray. The finding of Gram-positive rods in a Gram stain confirmed the diagnosis. The child required placement of multiple decompressive drains and fasciotomies, and was then transferred into the

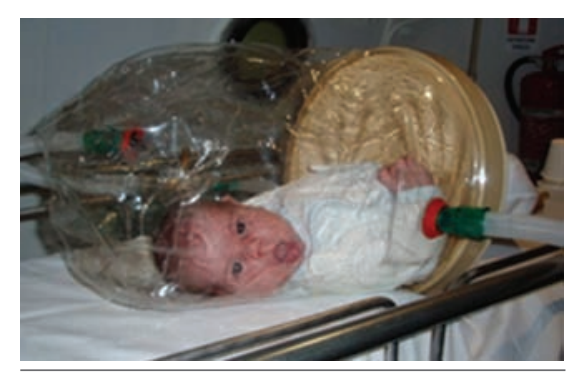

Figure 1. A child introduced from the belly to the head into a classic adult head helmet.

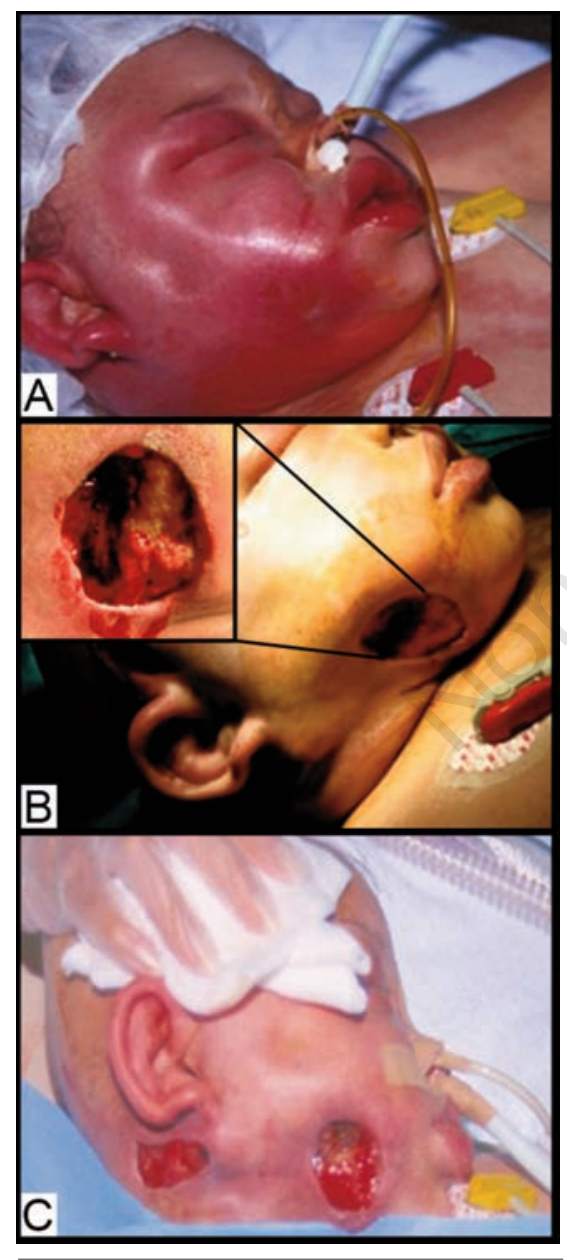

Figure 2. Hyperbaric oxygen treatment: $A$ ) a child with gas gangrene of the head/neck region; B) a child into the hyperbaric room (intubated and ventilated); C) respiratory stabilization. hyperbaric room, intubated and ventilated (Figure 2B). After $36 \mathrm{~h}$ of HOT and respiratory stabilization (Figure 2C), a surgical debridement with large removal of the infected and dead tissue was performed.

Group 2 included 2 infants with a perineal abscess associated to immunodeficiency secondary to chemotherapy for ALL and acute myeloid leukemia (AML), respectively. In both patients, incision and drainage of the abscess were carried out and the temporary colostomy was performed to protect the area before HOT to avoid the passage of stool through the anus and contamination of the perianal wounds.

Group 3 included 2 teenagers treated with HOT therapy for poor healing surgical wounds; both patients had recently undergone a thoracotomy for resection of pulmonary aspergilloma (patient n. 3.1) and a laparotomy due to intussusception (patient n. 3.2). At the time of surgery, both patients were immunodepressed. Wounds underwent repeated surgical debridement during HOT therapy, and subsequently healed.

Group 4 consisted of 2 children (patient $n$. 4.1 and patient n. 4.2), who underwent HOT therapy for skin ulcers due to arterial or venous insufficiency. Both patients had received chemotherapy for ALL. Skin ulcers took a very long time to heal. They were kept clear of dead tissue through repeated surgical cleaning. Topical antibiotics were used to prevent the ulcer becoming infected.

Group 5 included 2 children treated for postactinic injuries. Both patients had received brachytherapy after resection of soft tissue sarcoma (STS) of the forearm. During HOT therapy, they required a combined treatment consisting of surgical debridement and antibiotic therapy.

Group 6 included 2 adolescents with skin grafts and skin flaps at risk. Both had undergone excision of a large mass located on the limbs (respectively PNET-Ewing sarcoma and STS), with extensive loss of tissue and placement of a skin flap. Patient n. 6.2 discontinued HOT after 8 sessions because of the appearance of a metastatic skin nodule. No skin flap/graft was preserved despite early start of HOT, and a new surgical intervention was necessary.

\section{Discussion}

The efficacy of HOT therapy for skin and superficial soft tissue lesions is well documented in adults; however, there are very few data concerning the pediatric population with oncological diseases. Most scientific studies on children with oncological disease who underwent HOT therapy concern hemorrhagic cystitis, 12 brain abscesses 13 and aseptic

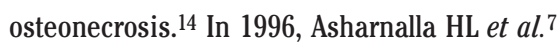
described one 10-year old child who underwent radiation therapy for cancer who had a radioinduced superficial soft tissue lesion, otherwise successfully treated with HOT therapy. In 2001, Johnston et al. ${ }^{10}$ presented 7 cases of NF associated with chemotherapy-induced neutropenia treated with broad-spectrum intravenous antibiotics, urgent surgical intervention and HOT therapy. In 2002, Fustes-Morales et al. ${ }^{11}$ reported 39 children with $\mathrm{NF}$ treated with HOT as adjuvant therapy. Just 3 of 39 had ALL as underlying factor. In 2006, Smith-Slatas et al. ${ }^{8}$ reviewed all reported pediatric cases in the English language literature with Clostridium septicum infection treated with HBO therapy as supportive therapy. They identified a total of 47 cases of Clostridium septicum infection and malignancies were found in $49 \%$ of the cases, with AML and ALL as the most common diagnoses.

In our series, the adult treatment regimens were successfully applied by simply decreasing the $\mathrm{O}_{2}$ pressure and tailoring the frequency of the sessions. ${ }^{1-4}$ In agreement with the international guidelines on HOT therapy, most patients started treatment as soon as they could, but the 2 children (patient ns. 1.1 and 1.2) who had a slight delay also obtained a good result. Concerning the $\mathrm{O}_{2}$ delivery system, we reported the successful use of the classic head helmet in infants. The number of HBT sessions varied and was very different also for the same disease, whereas its effectiveness, clinically evaluated during and at the end of treatment, appeared to be dependent on the disease. The effectiveness of HOT therapy was questionable in patients with skin graft and flaps at risk. Unfortunately, in both our cases (patients n. 6.1 and 6.2), HOT therapy started long after the first signs of cyanosis or reject and no pre-operative HOT therapy was carried out, as suggested by the international guidelines. ${ }^{7}$ Moreover, in one of these 2 patients, therapy was interrupted for the appearance of local skin metastases close to the site of primary tumor. It is questionable whether the HOT therapy could have favored their appeareance. However, there is no clear evidence that there is a link between HOT and the appearance of metastases. In vitro, in vivo and clinical studies strongly suggest that HOT therapy has no influence on tumor growth. ${ }^{15}$ This treatment increases tumor oxygenation and may, therefore, improve the radiation response of many solid tumors during radiotherapy, and also increase sensitivity to chemotherapy and photodynamic therapy. 16

In our series, HOT therapy was well tolerated and compliance was close to $100 \%$. Tolerance was improved by having physicians and sometimes family members accompany the children during all their treatment. The outcome in our series was excellent. All 
Table 1. Clinical features, schema and results of treatment.

\begin{tabular}{|c|c|c|c|c|c|c|c|}
\hline $\begin{array}{l}\text { Group n. } \\
\text { Patient n. }\end{array}$ & $\begin{array}{l}\text { Diagnosis/ } \\
\text { oncological } \\
\text { disease }\end{array}$ & $\begin{array}{l}\text { Age(yr)/ } \\
\text { Sex }\end{array}$ & $\begin{array}{l}\text { Adjunctive } \\
\text { therapy }\end{array}$ & $\begin{array}{l}\text { N. HOT } \\
\text { sessions/ } \\
\text { pressure }(A\end{array}$ & $\begin{array}{l}\text { HOT } \\
\text { local } \\
\text { TA) }\end{array}$ & \multicolumn{2}{|c|}{$\begin{array}{l}\text { Follow up Notes } \\
\text { (outcome/yr) } \\
\text { results }\end{array}$} \\
\hline 1.1 & Perineal NF/ALL & $2 / \mathrm{M}$ & $\begin{array}{l}\text { Antibiotics } \\
\text { Surgical debridement }\end{array}$ & $11 / 2.5$ & $\mathrm{CR}_{\mathrm{HOT}}$ & $\mathrm{CR} / 2$ & \\
\hline 1.2 & $\begin{array}{l}\text { Head-neck GG/ } \\
\text { Neuroblastoma }\end{array}$ & $8 / \mathrm{F}$ & $\begin{array}{l}\text { Antibiotics (penicillin) } \\
\text { Multiple percutaneous } \\
\text { decompressive drains } \\
\text { Fasciotomies } \\
\text { Myringotomy } \\
\text { Wide surgical excision }\end{array}$ & $30 / 2.5$ & $\mathrm{CR}_{\text {HOT }}$ & $\mathrm{CR} / 5$ & $\begin{array}{l}\mathrm{O}_{2} \text { delivery system: } \\
\text { endotracheal tube } \\
\text { Septic shock }\end{array}$ \\
\hline 2.2 & $\begin{array}{l}\text { Perianal } \\
\text { abscess/ALL }\end{array}$ & $<1 / \mathrm{M}$ & $\begin{array}{l}\text { Antibiotics } \\
\text { Abscess incision and drainage } \\
\text { Temporary oclostomy }\end{array}$ & $25 / 2$ & $\mathrm{CR}_{\mathrm{HOT}}$ & $\mathrm{CR} / 2$ & $\begin{array}{l}\mathrm{O}_{2} \text { delivery } \\
\text { system: head } \\
\text { helmet }\end{array}$ \\
\hline 2.3 & $\begin{array}{l}\text { Perianal } \\
\text { abscess/AML }\end{array}$ & $<1 / F$ & $\begin{array}{l}\text { Antibiotics } \\
\text { Abscess incision and drainage } \\
\text { Temporary colostomy }\end{array}$ & $27 / 2$ & $\mathrm{CR}_{\mathrm{HOT}}$ & $\mathrm{CR} / 9$ & $\begin{array}{l}\mathrm{O}_{2} \text { delivery system: } \\
\text { head helmet }\end{array}$ \\
\hline 3.3 & $\begin{array}{l}\text { Dehiscent surgical } \\
\text { wound: thoracotomy } \\
\text { for pulmonary } \\
\text { Aspergilloma/ALL }\end{array}$ & $12 / \mathrm{M}$ & $\begin{array}{l}\text { Antibiotics } \\
\text { Surgical debridement }\end{array}$ & $23 / 2.5$ & $\mathrm{CR}_{\mathrm{HOT}}$ & $\mathrm{CR} / 5$ & \\
\hline 3.4 & $\begin{array}{l}\text { Dehiscent surgical } \\
\text { wound: laparotomy } \\
\text { for intussusception/ } \\
\text { Burkitt's lymphoma }\end{array}$ & $12 / \mathrm{M}$ & $\begin{array}{l}\text { Antibiotics } \\
\text { Surgical debridement }\end{array}$ & $10 / 2.5$ & $\mathrm{CR}_{\mathrm{HOT}}$ & $\mathrm{CR} / 10$ & \\
\hline 4.1 & $\begin{array}{l}\text { Skin ulcers after } \\
\text { CT/ALL }\end{array}$ & $6 / \mathrm{M}$ & $\begin{array}{l}\text { Antibiotics } \\
\text { Surgical debridement }\end{array}$ & $56 / 2.5$ & $\mathrm{CRH}_{\mathrm{BOT}}$ & $\mathrm{CR} / 1$ & \\
\hline 4.2 & $\begin{array}{l}\text { Skin ulcers after } \\
\text { CT/ALL }\end{array}$ & $2 / \mathrm{F}$ & $\begin{array}{l}\text { Antibiotics } \\
\text { Surgical debridement } \\
\text { Myringotomy }\end{array}$ & $15 / 2.5$ & $\mathrm{CR}_{\mathrm{HOT}}$ & $\mathrm{CR} / 1$ & \\
\hline 5.1 & $\begin{array}{l}\text { Post-actinic } \\
\text { injuries/STS }\end{array}$ & $7 / F$ & Surgical debridement & $13 / 2.5$ & $\mathrm{CR}_{\mathrm{HOT}}$ & $\mathrm{CR} / 1$ & \\
\hline 5.2 & $\begin{array}{l}\text { Post-actinic } \\
\text { injuries/STS }\end{array}$ & $10 / F$ & Surgical debridement & $13 / 2.5$ & $\mathrm{CR}_{\mathrm{HBOT}}$ & $\mathrm{CR} / 10$ & \\
\hline 6.1 & $\begin{array}{l}\text { Skin flap/ } \\
\text { Ewing-PNET } \\
\text { Sarcoma }\end{array}$ & $16 / F$ & $\begin{array}{l}\text { Antibiotics } \\
\text { Surgical debridement }\end{array}$ & $8 / 3$ & $\mathrm{NR}_{\mathrm{HOT}}$ & AWD/1 & Further surgery \\
\hline 6.2 & $\begin{array}{l}\text { Skin flap/ } \\
\text { STS }\end{array}$ & $15 / F$ & $\begin{array}{l}\text { Antibiotics } \\
\text { Surgical debridement }\end{array}$ & $7 / 3$ & $\mathrm{NR}_{\mathrm{HOT}}$ & DOD/8 & $\begin{array}{l}\text { Stop HOT therapy } \\
\text { for appearance of } \\
\text { skin metastases } \\
\text { Further surgery }\end{array}$ \\
\hline
\end{tabular}

patients except 2 (83\%) responded very well. Comparable outcome was also reported in other pediatric retrospective analysis. ${ }^{7,9}$ In the study of Asharnalla et al., $90 \%$ of pediatric patients were successfully treated while Waisman et al., report $93 \%$ of pediatric patients were successfully treated.

It is difficult to draw conclusions from these retrospective data concerning a small series of patients with different diseases. In our experience, only patients with more severe complications underwent this therapy. The main limitation regards the evaluation of $\mathrm{HBO}$ effectiveness which was based only on the judgement of the physician during and at the end of the treatment. Moreover, it is difficult to assess the role of $\mathrm{HBO}$ in the whole treatment.

This study showed that HBO is a safe and effective supportive treatment if considered promptly for complex skin and superficial soft tissues pathologies involving multiple risk factors, such as those reducing the activation or efficacy of the immune system. It can reduce the need for further surgery and improve outcome after the occurrence of complications.

\section{References}

1. Tibbles PM, Edelsberg JS. Hyperbaric-oxygen therapy. N Engl J Med 1996;334:16428.

2. Feldmeier JJ. Hyperbaric oxygen 2003: indications and results- hyperbaric oxygen therapy committee report. Undersea and Hyperbaric Medical Society. Dunkirk, MD: Undersea and Hyperbaric Medical Society, 2003.
3. Vazquez RL, Spahr RC. Hyperbaric oxygen use in neonates. A report of four patients. Am J Dis Child 1990;144:1022-4.

4. Seidel M, Weiss M, Nicolai T, et al. Gas gangrene and congenital agranulocytosis. Pediatr Infect Dis J 1990;9:437-40.

5. Sawin RS, Schaller RT, Tapper D, et al. Early recognition of neonatal abdominal wall necrotizing fasciitis. Am J Surg 1994; 167:481-4.

6. Santamaria JP, Williams ET III, Desautels DA. Hyperbaric oxygen therapy in pediatrics. Adv Pediatr 1995;42:335-66.

7. Asharnalla HL, Goldwein JW, Thorn SR. Hyperbaric 0xygen Therapy for the Treatment of Radiation-Induced Sequelae in Children. The University of Pennsylvania Experience. Cancer 1996;77.

8. Smith-Slatas CL, Bourque M, Salazar JC. Clostridium septicum infections in chil- 
dren: a case report and review of the literature. Pediatrics. 2006;117:796-805.

9. Waisman D, Shupak A, Weisz G, Melamed Y. Hyperbaric Oxygen Therapy in the Pediatric Patient: The Experience of the Israel Naval Medical Institute. Pediatrics 1998;102.

10. Johnston DL, Waldhausen JH, Park JR. Deep soft tissue infections in the neutropenic pediatric oncology patient. J Pediatr Hematol Oncol 2001;23:443-7.

11. Fustes-Morales A, Gutierrez-Castrellon P, Duran-Mckinster C. Necrotizing fasciitis: report of 39 pediatric cases. Arch Dermatol 2002;138:893-9.

12. Decker DB, Karam JA, Wilcox DT. Pediatric hemorrhagic cystitis. J Ped Urol 2009;5: 254-64.

13. Lackner H, Sovinz P, Benesch M, Management of brain abscesses in children treated for acute lymphoblastic leukemia. Pediatr Blood Cancer 2009;52:408-11.

14. Lackner H, Benesch M, Moser A, et al. Aseptic osteonecrosis in children and adolescents treated for hemato-oncologic dis- eases: a 13-year longitudinal observational study. J Pediatr Hematol Oncol 2005;27: 259-63.

15. Feldmeier J, Carl U, Hartmann K, Sminia P. Hyperbaric oxygen: does it promote growth or recurrence of malignancy? Undersea Hyperb Med 2003;30:1-18.

16. Al-Wahili NS, Butler GJ, Beale J, et al. Hyperbaric oxygen and malignancies: a potential role in radiotherapy, chemotherapy, tumor surgery and phototherapy. Med Sci Monit 2005;11:RA279-89. 